Psychology is another subject that in several ways can assist the engineer in carrying on his work effectively. In industrial organizations, work cannot be done efficiently without a thorough knowledge of human nature. The depression has emphasized the importance of this. Although the study of psychology will not correct all personal shortcomings, yet it seems the only practical way by which the colleges can bring about improvement. A few specific lectures on this subject would be helpful in a school of engineering, but, at least at first, they should not be made compulsory.

Graduate courses at college prior to entering industry are, in Mr. Hellmund's opinion, only of limited value. It is dangerous for an engineering student to stay too long in a college atmosphere. The profession is one which requires courage and initiative, qualities which are rarely developed in college life by the type of students who take postgraduate courses. It is true that there are a few kinds of highly technical research work which might advantageously be done at a postgraduate course at the university. If the postgraduate work is undertaken because the graduate is unable to find immediate employment in industry, it is advisable not to take courses in the specific subjects of the branch of engineering contemplated but in affiliated subjects. For example, an engineer wishing to enter research work on electrical subjects would do well to take additional mathematies, physics and physical chemistry. One intending to take up practical design would find additional work relating to the materials used in his type of engineering, such as chemistry and metallurgy, very useful. The opinion is expressed that it is generally better for the young engineer to enter industry as soon as possible after completing his undergraduate course.

During the depression, the business of many industries deereased by $20-60$ per cent of previous levels. The heavy industries were as a rule the most severely affected. During the lowest level, it was difficult for engineering graduates to find employment. Now industry is increasing and the prospects are good. As a rule, employers can engage their old employees with specific experience and ability, but some of these have taken up activities outside the engineering industry and so there is a demand for young engineers. In some cases the latter have a great advantage over the older men, as they know the latest theories and methods and have not forgotten how to handle the technical details in calcu. lations, laboratory and similar work.

Mr. Hellmund has noticed that about seventy per cent of all engineering graduates express a desire to go into power transmission work, the design of large machinery, railway electrification and similar work. As they all cannot get employment in this direction, it is necessary to persuade some of them to take up other activities. The author can recall no instance where the men who took his advice afterwards regretted their action, as they soon found that there are very interesting and important problems in almost every branch of engineering. The young engineer need not fear to enter work not entirely in accord with his wishes. He should prepare himself to handle effectively the work assigned to him.

\title{
Chemistry of Fibres
}

$\mathrm{T}$ HREE papers read at the annual conference of the Textile Institute held in London on June 3-6 dealt with various aspects of the chemistry of fibres.

One of these was a comprehensive summary by G. F. Davidson of current theories of the molecular structure of cellulose. After an outline of the chemical and physical evidence in support of the molecular chain theory, the membrane theory of Hess was dealt with critically; the author, in common with most other investigators, appears to prefer the former. Six methods for the determination of the molecular weight of cellulose and its derivatives were then described, and the difficulty of correlating and interpreting the resulting values was emphasized. Thus, chemical determinations of end-groups give the 'molecular weight' of the largest unit within which the atoms are bound by primary valencies; osmotic pressure and ultra-centrifuge methods measure only particle size and, therefore, depend on the degree of aggregation of the molecules; whilst viscosity measurements must be standardized against an absolute method.

The second part of the paper described how the methods devised by the British Cotton Industry Research Association for the preparation of modified cotton cellulose by the action of acids and oxidizing agents have enabled evidence in support of the chain theory to be obtained.

A second paper, entitled "Wood Pulp for the Rayon Industries", by L. Hebbs, contained some interesting side-lights on the influence of the early work of the late C. F. Cross. Thus, it was pointed out that so long ago as 1904 a pulp with an $\alpha$-cellulose content of 88.8 per cent had been produced by mercerization with alkali. Moreover, in 1906 an analytical method for the determination of $\alpha$-cellulose was outlined, which is essentially the same as that used to-day. The correlation of the copper number and the cuprammonium- and viscose-viscosities with the strength and cellulose purity of pulp was then discussed, the relationships being illustrated graphically. The elimination of resinous matter in the manufacture of wood pulp is greatly assisted by removal by washing and screening of the small sacs, medullary rays and short fibres in which it is concentrated, and by bleaching the pulp in several stages. Rapid replacement of cotton linters by wood pulp is expected.

In the third paper, Dr. R. Cuthill discussed the sorptive properties of the silk fibre, which are of considerable importance both from a theoretical and a practical point of view. Gases and vapours, nonelectrolytes in solution and pure liquids, suspended solids, electrolytes and dyes were dealt with in turn. 